\title{
A Study on the Influencing Relationship of Key Factors in CRM
}

\author{
Wenxing Wang ${ }^{1,2}$, Shuying $\mathrm{Sun}^{3}$ and Xianglu $\mathrm{Li}^{2}$ \\ 'Glorious Sun School of Business and Management, Donghua University, Shanghai 200051, \\ P.R.Chinawwx222@126.com \\ ${ }^{2}$ College of Economics and Management, Zhongyuan Technology Institute, Zhengzhou \\ 450006, P.R. China \\ ${ }^{3}$ College of Wood Science and Technology, Nanjing Forestry University, Nanjing 210037, \\ P.R. China
}

\begin{abstract}
In today's highly competitive business world, customer relationship management (CRM) is emerging as a core marketing activity. Based investigation of the factors that influence the customers' willingness to engage in a relationship (CWER) and the customer relationship share (CRS), a conceptual model is derived by using theories taken from multi-disciplinary literature, including marketing, management, information systems, and ecommerce. It is mainly tested to determine (1) the effect of CWER and the customer satisfaction (CS) on CRS; (2) the effect of customers' attitude toward the firm on CWER; and (3) how customers' knowledge and belief about CRM program affect customers' attitude. Finally, this study also provides a framework for several avenues for scholarly research and lays a foundation for future research aimed at enhancing extant knowledge about factors influencing CWER and RS.
\end{abstract}

Keywords: Customer relationship management (CRM), Customer satisfaction (CS). Customers' Willingness to engage in a relationship (CWER), Customer relationship share (CRS)

\section{INTRODUCTION}

In today's highly competitive business world, both CRM and excellence in customer service are strategically important. Some researchers have analyzed customers' lifetime behavior in contractual contexts [1]. However, research is scarce on how to enhance CWER and RS [2] with the firm. The need to focus on CWER and $\mathrm{RS}$, and, thus, to measure the CRM effectiveness, has been strongly expressed by scholars [3].

The objective of this study is to identify the important determinants of CWER and RS and to empirically test if CWER enhance RS. This study proposes a conceptual framework, develops and tests a model to explain the antecedents of RS and CWER with the firm and how SAT, leads to RS. 


\section{LITERATURE REVIEW}

Identifying customers and establishing relationships with them has made a great leap forward during the past decade. But, little is known regarding the identification of the drivers of CWER and RS. Customer satisfaction, trust, commitment, and customers' experience with the firm have become focal constructs in relationship marketing research [4-7]. But, there are few scholarly studies that discuss the factors that enhance CWER and RS in the context of CRM. Research has shown that in CRM, customer' attitude toward the firm is one of the most important factor in establishing CWER with the firm [5], which leads to increase in RS. Customer RS can also be enhanced by increasing customer satisfaction and their CWER with the firm.

We propose a research model, shown later in Figure 1, which illustrates relationships between key factors in CRM. Three theoretical perspectives are used to support this study: commitment theory given by Becker [8], attitude representation theory [9-10], and planned behavior theory [11-12].

\section{SAMPLE CHARACTERISTICS}

The sample consists of customers own a cell phone. An online data collection firm assisted in data collection. From a sample frame of 30,094 customers, the online firm sent the questionnaire to 2,148 customers, using a random sampling method. The sample frame comprised customers from all parts of China.

A total of 2148 emails were sent to the subjects, 585 completed and submitted them. Thus, the response rate for this study was $27.2 \%$. The subjects for the study consisted of slightly more female $(55 \%)$ than male $(45 \%)$. The youngest participants were in the age group 18-24 years which constituted $5.5 \%$ of the total responses whereas the majority of the participants in this study were in the age groups of 35-44 years, 45-54 years, and 55-64 years which constituted $21.7 \%, 25.1 \%$, and $22.2 \%$ of the total responses. A majority of the subjects, approximately $84 \%$ for this study, fell in the last four educational categories (some college and beyond), thus indicating that a large number of respondents were highly educated. Approximately $40 \%$ of the respondents had a household income between $¥ 50,000 \sim ¥ 99,999$.

\section{STRUCTURAL MODEL AND ANALYSIS}

\subsection{Structural Model}

Five constructs (satisfaction, customer knowledge and belief about the CRM program, customers' attitude toward the firm, customers' willingness to engage in a relationship, and relationship share), and seventeen measured variables were used for 
model testing. Since the normalized estimate of multivariate kurtosis was found to be 91.55 in the proposed model, which exceeded the recommended cutoff point of 3 , Robust Maximum Likelihood (ML) estimation method, as suggested by Schumacker and Lomax [13], was used for model testing.

Multiple fit indices, as suggested by Schumacker and Lomax [13], were used for assessing the model fit of the final revised structural model. The results indicated that the overall fit indices of the structural model (Figure 1) were excellent, indicating a close fit. The Satorra Bentler Chi square ratio (S-B x2 /df) statistic of 2.23 was found to be within the acceptable range of 3 . The other fit indices also indicated a close model fit. All the fit indices, including incremental fit index (IFI), comparative fit index (CFI), and non-nonmed fit index (NNFI) values, were above .90 as recommended by the literature. The root mean square error of approximation (RMSEA) was below 0.05 thus indicating a close model fit [14-15]. Table 1 shows the summary statistics, model fit, of the final revised model.

Table 1. Summary Statistics of the Final Revised Model

\begin{tabular}{|c|c|c|c|}
\hline Fit Indices & Acceptable level & Threshold level & $\begin{array}{l}\text { Final revised } \\
\text { model }\end{array}$ \\
\hline $\begin{array}{cc}\text { S-B } \\
\text { square/df }\end{array}$ & 1 to 3 & $<3$ & 2.23 \\
\hline CFI & $\begin{array}{l}0 \text { (no profit) to (perfect } \\
\text { fit)! }\end{array}$ & $>0.90$ & 0.980 \\
\hline NFI & $\begin{array}{l}0 \text { (no profit) to (perfect } \\
\text { fit) } 1\end{array}$ & $>0.90$ & 0.964 \\
\hline NNFI & $\begin{array}{l}0 \text { (no profit) to (perfect } \\
\text { fit) } 1\end{array}$ & $>0.90$ & 0.975 \\
\hline RMSEA & $\begin{array}{l}0 \text { (no profit) to (perfect } \\
\text { fit) } 1 \\
\text { (acceptable fit) }\end{array}$ & $<0.08$ & 0.046 \\
\hline
\end{tabular}

\subsection{Testing of the Hypotheses}

Testing of the hypotheses involves confirming that a theoretically specified model fits sample data. The causal relationships between the five constructs were examined. The proposed/base model is shown in Figure 1 .Five hypothesized paths (parameters) were tested for significance in this study. The summary of the five hypothesized paths are shown in Table 2.

First the directionality of the parameters were examined to determine whether they have the correct sign (either plus or minus) and then the magnitude of the paths (or parameter estimates) between the constructs were examined to determine whether they were out of bounds or exceeded an expected range of values [13].

Once the directionality and magnitude were examined then the statistical significance of the hypothesized paths (parameter estimates) were investigated by examining the path coefficients, t-value, and standard error (SE). The paths (or parameters) estimates of the structural model are shown in figure 1. 
Table 2. Summary of Hypotheses

\begin{tabular}{cl}
\hline Hypotheses & $\begin{array}{c}\text { The greater the customers' willingness to engage in a } \\
\text { H1:CWER } \rightarrow \text { RS }\end{array}$ \\
H2: SAT $\rightarrow$ RS & $\begin{array}{l}\text { relationship (CWER) with a firm, the higher the customers } \\
\text { relationship share (RS) with that firm. } \\
\text { The higher the customer satisfaction (SAT), the greater } \\
\text { the customers relationship share (RS) with the firm. } \\
\text { The higher the customer satisfaction (SAT), the more } \\
\text { positive their attitude (ATT) toward the firm. } \\
\text { The greater the customers' knowledge and belief about }\end{array}$ \\
H3: SAT $\rightarrow$ ATT & $\begin{array}{l}\text { a firm's CRM program (KNOW), the more positive the } \\
\text { customers' attitude (ATT) toward the firm. } \\
\text { The more positive the customer's attitude (ATT) toward }\end{array}$ \\
KNOW $\rightarrow$ ATT & $\begin{array}{l}\text { a firm, the greater the customer's willingness to engage in a } \\
\text { relationship (CWER) with the firm. }\end{array}$ \\
ATT $\rightarrow$ CWER &
\end{tabular}

\subsection{Parameter Estimates or Path Analyses}

Five hypothesized paths, between the five latent constructs (satisfaction, knowledge, attitude, willingness, and relationship share), were tested for significance. According to different studies [16-17], a path is considered significant if the t-value (parameter estimates divided by standard error of the parameter estimates) is significant. If the parameter estimate is positive and significant, it indicates that there is a positive relationship and if the parameter estimate is negative and significant, it means that there is inverse relationship between the constructs.

The result indicated that all the five hypothesized paths that were tested, in this study, were significant and the directionality of all those significant hypothesized paths was positive. The result for the structural model is shown in Figurel. The structural model shows the significant paths. Out of the five significant paths, two paths (SAT $\rightarrow$ ATT and ATT $\rightarrow$ CWER) were significant at 0.01 level and the $t$-values for those two paths were 8.83 and 8.54 respectively. Two paths (CWER $\rightarrow$ RS, and $\mathrm{SAT} \rightarrow \mathrm{RS}$ ) were significant at 0.05 level. The $t$-values for those significant paths were 1.82 and 1.66 respectively. One path $(\mathrm{KNOW} \rightarrow \mathrm{ATT})$ was significant at 0.10 level and the $\mathrm{t}$-value was 1.37 . 


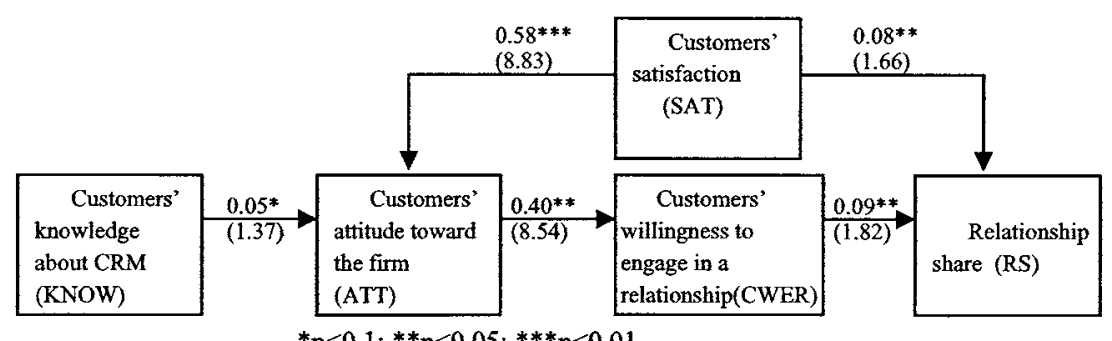

Figure 1. Key Factors Relationship Model

Figure 1 shown above presents the model and structural path coefficients for each relationship. The structural model result indicated proposed at $\mathrm{p}<0.01, \mathrm{p}<0.05$, and $\mathrm{p}<$ 0.10 levels.

It supports all the five hypotheses as below:

Hypothesis 1, predicting a positive relationship between customers' willingness to engage in a relationship (CWER) and relationship share (RS) was supported. The results revealed that the path between these two latent variables was positive $(\beta 32=0.09)$ and significant $(\mathrm{p}<0.05)$, thus supporting hypothesis 1 .

Hypothesis 2 and 3 are related to satisfaction. The analysis indicated a significant direct effect for satisfaction (SAT) to relationship share (RS) and customers' attitude toward the firm (ATT). Test results indicated that satisfaction (SAT) has direct effect on relationship share $(\gamma 23=0.08 ; p<0.05)$ and customers' attitude toward the firm $(\gamma 21=0.58 ; \mathrm{p}<0.01)$. Thus, hypotheses 2 and 3 were supported.

Hypothesis 4 predicting a positive relationship between customers' knowledge and belief about the CRM program (KNOW) and customers' attitude (ATT) was supported. Test results revealed that KNOW has direct effect on customers' attitude $(\gamma 11=0.05 ; \mathrm{p}<0.1)$ and is significant, thus supporting hypothesis 4 .

From Figure 1 above, it can be said that customers' attitude (ATT) toward the firm was a predictor of customers' willingness to engage in a relationship (CWER), which supports hypothesis 5 . The path between these two latent constructs is positive $(\beta 12=0.40 \mathrm{p}<0.01)$ and significant.

Thus, results revealed that five hypothesis were supported.

\section{CONCLUSIONS}

To reduce the high failure rate of CRM program, this study provides important insights for managers. The results shown in the model developed for this study suggest that managers may be able to influence the achievement of desired outcomes from a CRM program in ways. It also have identified important factors which can be used by managers formulate marketing strategies aimed at achieving CWER and higher customer RS.

Firms should devote more attention to developing and maintaining relationships with customers which enhance customer satisfaction. This enhancement of customer satisfaction should result in: (1) positive attitude of the customers toward the firm; (2) 
an increase in customers' willingness to engage in a relationship (CWER) with the firm, and (3) increased customer relationship share (RS) for that firm. Overall, this strategy should enable firms to maximize customers' repeat business and subsequent profits.

\section{REFERENCES}

1. Allenby, M.G. Leone, P. Robert, and J. Lichung, A Dynamic Model of Purchase Timing with Application to Direct Marketing, Journal of the American Statistical Association. Volume 94, Number 446, pp.365-374, (1999).

2. Reinartz, J. Werner, and V. Kumar, The Impact of Customer Relationship Characteristics on Profitable Lifetime Duration, Journal of Marketing. Volume 67, Number 1, pp.77-99, (2003).

3. J. Rajnish, J. Sangeeta, and D. Upinder, Measuring Customer Relationship Management, Journal of Service Research. Volume 2, Number 2, pp.97-109, (2003).

4. Doney, M. Patricia, and C.P. Joseph, An Examination of the Nature of Trust in BuyerSeller Relationships, Journal of Marketing. Volume 61, Number 2, pp.35-51, (1997).

5. E. Garbarino, and M.S. Johnson, The Different Roles of Satisfaction Trust, and Commitment in Customer Relationships, Journal of Marketing. Volume 63, Number 2, pp.70-87, (1999).

6. A. Morgan, M. Robert, and H.D. Shelby, The Commitment-Trust Theory of Relationship Marketing, Journal of Marketing. Volume 58, Number 3, pp.20-38, (1994).

7. C. Moorman, R. Deshpande, and G. Zaltman, Factors Affecting Trust in Market Research Relationships, Journal of Marketing. Volume 57, Number 1, pp.81-100, (1993).

8. H.S. Becker, Notes on the Concept of Commitment, American Journal of Sociology. Volume 66, pp.32-40, (1960).

9. C.G. Lord and M.R. Lepper, Attitude Representation Theory, Advances in Experimental Social Psychology. Volume 31, pp.265-343, (1999).

10. S.L. Tiffiny, K.A. Blessum, J.C. Thomas, and M.R. Lepper, Activation of Exemplars in the Process of Assessing Social Category Attitudes, Journal of Personality \& Social Psychology. Volume 76, pp.517-532, (1999).

11. I. Ajzen, The Theory of Planned Behavior, Organizational Behavior \& Human Decision Processes. Volume 50, Number 2, pp.179-212, (1991).

12. I. Ajzen and M. Fishbein, Understanding Attitudes and Predicting Social Behavior (Englewood-Cliffs, Prentice Hall: NJ, 1980).

13. Schumacker, E. Randall, and R.G. Lomax, A Beginner's Guide to Structural Equation Modeling, 2nd ed. (Lawrence Erlbaum Associates, Inc: New Jersey, 2004).

14. Bentler, M. Peter, and K. Yuan, Structural Equation Modeling with Small Samples: Test Statistics, Multivariate Behavioral Research. Volume 34, Number 2, pp.181-197, (1999).

15. H. Baumgartner, C. Homburg, Applications of Structural Equation Modeling in Marketing and Consumer Research: A Review, International Journal of Research in Marketing. Volume 13, Number 2, pp. 139-161, (1996).

16. P. Munn, Tiffany, L. Aksoy, T.L. Keiningham, and D. Estrin, Actual Purchase as a Proxy for Share of Wallet, Journal of Service Research. Volume 7, Number 3, pp.245-256, (2005).

17. L.A. Hayduk, Structural Equation Modeling with LISREL (John Hopkins University Press: Baltimore, 1987). 